\title{
DISCUSSION
}

\section{Influence of curing under stress on the triaxial response of cemented soils}

\author{
N. C. COnsoli, G. V. ROTtA and P. D. M. PRIETTO (2000). Géotechnique 50, No. 1,99-105
}

\section{T.-W. Feng, Chung Yuan Christian University, Republic of China}

The authors have shown the results of an experimental study on the triaxial response of artificially cemented sands. Basically, the authors prepared two groups of soil-cement specimens that were cured without stress or under stress for $48 \mathrm{~h}$. Subsequent triaxial tests determined the strength and stress-strain properties of these specimens. Since most of the conclusions were drawn from the test results, it is important to know about the test method in much more detail than that reported by the authors. First, it is not known how the rapid-hardening Portland cement was mixed with the silty sand sample. Was the cement mixed with the sand in its powder state or in a slurry state? Second, it is not known how much time elapsed from the beginning of the soil-cement mixing until the end of the undercompaction. If the specimens were made in six sub-layers by the undercompaction method, the bottom sub-layer would have more cementing bonds than other sub-layers since it was prepared first. Thus it may not be possible to obtain a homogeneous specimen by using the undercompaction method. Unlike the authors' description, the writer believes that significant cementing bonds would have been formed in the specimens of the second group (cured under stress) before they were consolidated, especially when the rapid-hardening Portland cement was used. Third, it is not known whether both groups of specimens were connected to the drainage line during curing. It can be seen from Table 1 that the specimens cured without stress have lower water contents and degrees of saturation than those of the specimens cured with stress. The differences in the water content and the degree of saturation can lead to some differences in the developed cementing bonds.

There is no doubt that the specimens cured without stress should be weaker than the specimens cured under stress. The main reason for this is that the specimens cured under stress will have undergone volume reduction at the beginning of curing and therefore are denser than the specimens cured without stress before shearing. This is evidenced by the stress-strain curves and the curves of volumetric strain against axial strain for the two specimens sheared under $50 \mathrm{kPa}$ of consolidation pressure (Figs 1(a) and 1(b)). The stress-strain curve of the specimen cured under stress shows a large-strain principal stress difference of $310 \mathrm{kPa}$, whereas the stress-strain curve of the specimen cured without stress shows a large-strain principal stress difference of $200 \mathrm{kPa}$. The curve of volumetric strain against axial strain for the specimen cured under stress is still climbing at an axial strain of $6 \%$, whereas that for the specimen cured without stress has already levelled off at this strain. Furthermore, the volumetric strain of the specimen cured under stress is larger than that of the specimen cured without stress. These observations all indicate that the specimen cured and sheared under $50 \mathrm{kPa}$ of consolidation pressure is denser than the corresponding specimen cured without stress. The same reasoning applies to the specimens sheared under $250 \mathrm{kPa}$ and $500 \mathrm{kPa}$ of consolidation pressures. Therefore the authors are using test results from specimens of different densities, but they have not taken this factor into consideration in their analysis of the test results.

The caption 'strength envelopes' of Fig. 4 is misleading, since the strength envelope is generally referred to as the curve tangent to the Mohr circles at failure. The $p^{\prime}-q$ relationship shown in Fig. 4 is the $M$ line defined by Schofield \& Wroth (1968). It is not the same as the $k_{\mathrm{f}}$ line defined by Lambe \& Whitman (1969). By using the test data from the discussed paper, both peak strength and large-strain strength $k_{\mathrm{f}}$ lines are shown in Fig. 7, in which $s^{\prime}=\left(\sigma_{1}^{\prime}+\sigma_{3}^{\prime}\right) / 2$ and $t=\left(\sigma_{1}^{\prime}-\sigma_{3}^{\prime}\right) / 2$. Values of the angles of internal friction, $\phi_{\mathrm{p}}^{\prime}$ and $\phi_{1}^{\prime}$, and the cohesion intercepts, $c_{\mathrm{p}}^{\prime}$ and $c_{1}^{\prime}$, for peak and large-strain conditions are also indicated in Fig. 7. It can be seen from Fig. 7 that, although the definitions of $p^{\prime}$ and $q$ in the figure are different from those in the paper, the determined peak strengths are the same. While $c_{\mathrm{p}}^{\prime}$ seems to be independent of the curing conditions, the specimens cured under stress present a slightly higher $\phi_{\mathrm{p}}^{\prime}$ because they were denser than the specimens cured without stress.

The strength of cemented sands under large shearing strain deserves further discussion, since progressive failure may occur in cemented soils. It can be seen clearly from Fig. 7 that the values of large-strain cohesion, $c_{1}^{\prime}$, are much smaller than the values of peak cohesion, $c_{\mathrm{p}}^{\prime}$, and the values

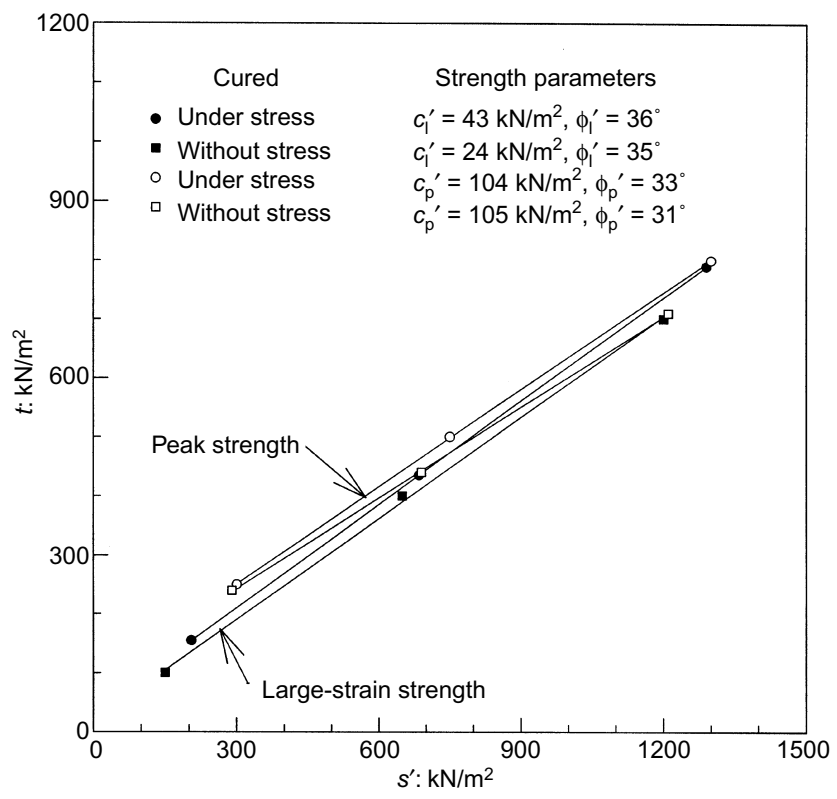

Fig. 7. Peak strength and large-strain strength plots of $s^{\prime}$ against $t$ 
of large-strain angle, $\phi_{1}^{\prime}$, are slightly larger than the values of peak angle, $\phi_{\mathrm{p}}^{\prime}$. The reduction of cohesion from $c_{\mathrm{p}}^{\prime}$ to $c_{1}^{\prime}$ is apparently due to breaking of the cementing bonds. Similar behaviour has been observed from the failure envelopes of overconsolidated and normally consolidated soft clays (e.g. Terzaghi et al., 1996). It is also observed from Fig. 7 that curing under stress increases large-strain cohesion but does not affect the large-strain angle of internal friction. This is interesting, since it is the opposite of the peak strength behaviour described by the authors. However, it is believed that further data points with different values of $\sigma_{3}^{\prime}$, both smaller and larger than the yield stress of $250 \mathrm{kPa}$, would be helpful to define better both the authors' peak strength $M$ lines (in Fig. 4) and the $k_{\mathrm{f}}$ lines in Fig. 7. It is of interest to compare these values of $\phi_{1}^{\prime}$ and $\phi_{\mathrm{p}}^{\prime}$ with the value of $\phi^{\prime}$ for the test sand without cementation.

The value of $c_{1}^{\prime}$ for the specimens cured under stress is $43 \mathrm{kPa}$, which is about twice that for the specimens cured without stress, and neither of them is equal to zero. This implies that the field large-strain cohesion of cemented sands is still greater than zero. For naturally cemented sands, some of the cementing bonds may be broken as a result of sampling, so that the peak strength is reduced. Applying in situ stresses to the specimens taken from the field could not restore broken cementing bonds.

In summary, the triaxial test results suggest that the density of the artificially cemented sand specimen is increased during curing under stress. Thus the authors' conclusions with regard to the effects of curing condition on the stiffness, cohesion and peak angle of internal friction of the artificially cemented sand specimens are still a subject that needs further study. It is important to control the density of the specimens to study the effect of curing conditions. The triaxial test results further show that the large-strain cohesion for the specimens cured under stress is much greater than that for the specimens cured without stress. This suggests the necessity of using specimens cured under stress to study the field behaviour of cemented sands.

\section{Authors' reply}

The authors would like to thank the discusser for his valuable comments concerning the results presented in the technical note.

The discusser initially suggests that the authors' findings might be somehow prejudiced by some of the experimental procedures used. For the sake of clarity, further details about specimen preparation and curing method are provided.

The specimens were prepared by initially mixing the relevant quantities of dry soil and powdered Portland cement; the water was then added to the mixture, and further mixing was performed until homogeneity had been guaranteed. Next, the soil-cement mixture was dynamically compacted, at the specified density, in three layers into a $50 \mathrm{~mm} \times 100 \mathrm{~mm}$ cylindrical mould. Immediately after moulding, all the specimens were set into the triaxial chamber to cure before testing. At the very beginning of the curing process, half the specimens, which were identified as cured under stress, were allowed to consolidate under a confining stress applied $\left(50,250\right.$ or $\left.500 \mathrm{kN} / \mathrm{m}^{2}\right)$; the rest of them, identified as cured without stress, were submitted only to a confining stress of $10 \mathrm{kN} / \mathrm{m}^{2}$. All the specimens were then left to cure for $48 \mathrm{~h}$ before being sheared under the confining pressures of 50,250 or $500 \mathrm{kN} / \mathrm{m}^{2}$. It should be emphasised that the time interval between water addition to the soil-cement mixture and the end of the consolidation under the curing stress applied was always less than $1 \mathrm{~h}$.

The discusser argues that some of the cementation bonds were probably formed during the compaction process and hence, for the specimens cured under stress, before the curing stresses were applied. Also, he points out that small differences in moisture content, as reported in Table 1, might give rise to significant differences in the quantity of cementation bonds formed, since the amount of water needed for completely hydrating the Portland cement might not have been provided to the specimens.

The authors are aware that the hydration of Portland cement starts immediately after water is poured into it. However, the setting time - that is, the time when the cement-water paste starts to stiffen-for rapid-hardening cement is usually greater than $60 \mathrm{~min}$ (110 minutes for the sample used), which is sufficiently longer than the time allowed between specimen preparation and the end of the consolidation under curing confining stress. Regarding the amount of water demanded to hydrate the Portland cement completely, this is found to be about $30 \%$ of the cement mass (e.g. Mehta \& Monteiro, 1993), while for the soilcement mixture reported in the technical note it was as high as $650 \%$. Consequently, significant cementation bonds were expected to occur long after the specimen had been consolidated under the curing stress applied. To corroborate this, Fig. 8 shows isotropic compression curves obtained for the same artificially cemented soil presented in the technical note, cured under confining stresses ranging from 250 to $1000 \mathrm{kN} / \mathrm{m}^{2}$, as well as for an uncemented reference specimen $(0 \%$ cement $)$. The cemented specimens were initially consolidated under the curing stress applied and then allowed to cure inside the triaxial chamber for $48 \mathrm{~h}$, before being tested. The first point plotted in each curve corresponds to the state of the specimen at the end of the curing process and the beginning of isotropic compression. It can be readily seen that these points lie roughly on the isotropic compression curve obtained for the uncemented specimen, demonstrating that the cemented specimens, when consolidated under the curing confining stress, behaved similarly to the uncemented reference specimen.

The discusser also questions the correctness of the failure envelopes presented in Fig. 4, and suggests the form pictured in Fig. 7 as the correct one. In fact the authors have chosen to use the stress invariants $p^{\prime}$ and $q$ defined as follows, which are understood to be the more appropriate variables to describe triaxial stress-strain states (e.g. Wood, 1990):

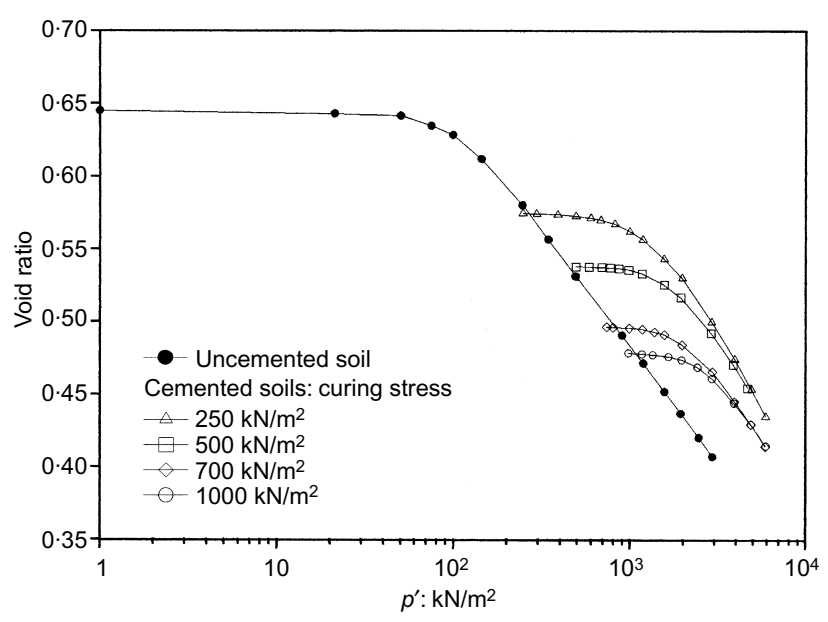

Fig. 8. Isotropic compression curves for the artificially cemented soil cured under different stresses and for the uncemented soil 


$$
\begin{aligned}
& p^{\prime}=\frac{\sigma_{1}^{\prime}+2 \sigma_{3}^{\prime}}{3} \\
& q=\sigma_{1}^{\prime}-\sigma_{3}^{\prime}
\end{aligned}
$$

where the principal stresses $\sigma_{1}^{\prime}$ and $\sigma_{3}^{\prime}$ correspond in the conventional compression triaxial test to the axial stress and radial stress respectively.

The authors do agree with the discusser about the reasons why the specimens cured under stress are stronger than those cured without stress. The first reason is undoubtedly breakage of the cementation bonds during isotropic compression of the specimens cured without stress, which was broadly discussed in the technical note. The second reason is the change in density associated with the curing under stress, which has been further investigated by the authors in a follow-up work. To make this point clearer, Fig. 9 shows a new set of triaxial tests carried out on artificially cemented specimens cured under different stresses (50, 250 and $500 \mathrm{~N} / \mathrm{m}^{2}$ ) but sheared at the same confining stress $\left(50 \mathrm{kN} / \mathrm{m}^{2}\right)$. The specimens have the same characteristics as those reported in the technical note except for the compaction method: static compaction was used. Fig. 9 allows the reader an unbiased assessment of the influence of the change in density associated with curing under stress, since there is no possibility of the cementation bonds breaking during isotropic compression. As the density increases with increasing curing stress, the cemented soil becomes stiffer, more resistant, and dilatant. The authors believe that, as well as the obvious effect of void ratio reduction, there is an increase in the quantity of cementation bonds formed, since the number of interparticle contacts is likely to increase with increasing density, in agreement with what is suggested in recent work by Huang \& Airey (1998).

Finally, the uncemented soil, compacted at a comparable initial density and tested at the same confining stresses, has a peak friction angle of $30^{\circ}$, which is similar to the value obtained for the cemented soil cured without stress $\left(31^{\circ}\right)$. This is in agreement with the general understanding that the friction angle is not significantly affected by cementation (e.g. Clough et al., 1981). Nevertheless, when compared with the value obtained for the cemented soil cured under stress $\left(33^{\circ}\right)$, it can be concluded that the cementation by itself actually increases the friction angle of the uncemented soil. It should be noticed that the initial density at shearing is expected to be the same for both the uncemented and the cemented soil cured under stress (as seen in Fig. 8), when these are tested at the same confining stress. Therefore the increase in friction angle results not from any change in density but from an increase in cementation bonds with increasing confining stress.
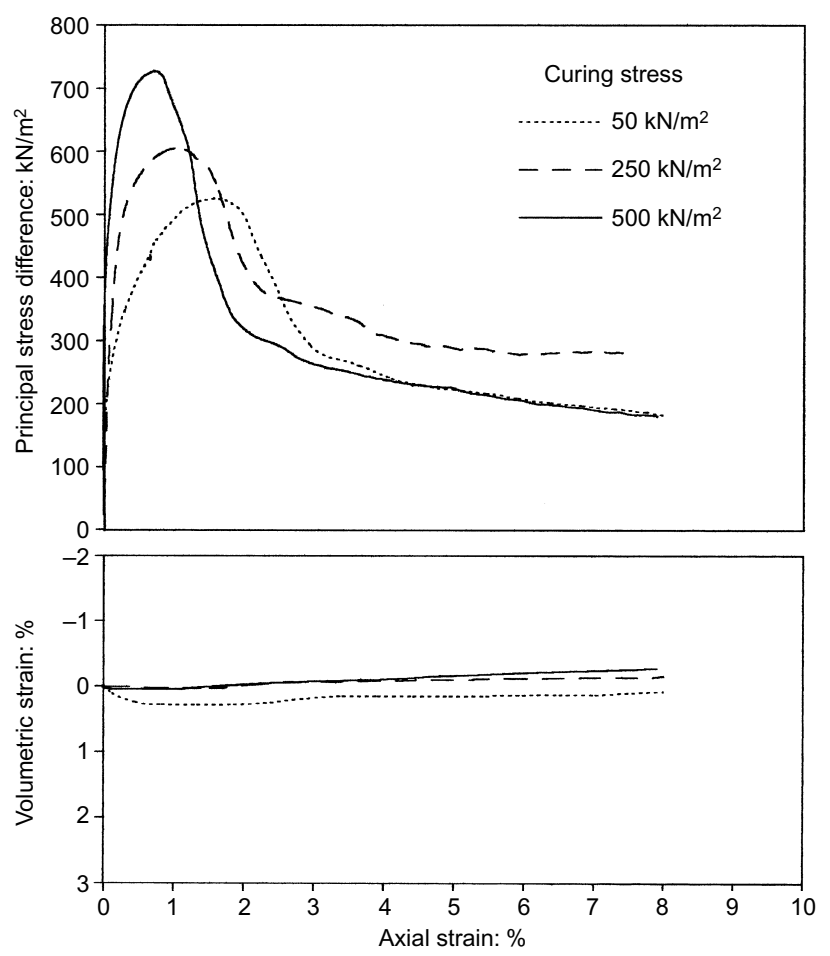

Fig. 9. Triaxial response for the artificially cemented soil cured under different stresses $\left(50,250\right.$ and $\left.500 \mathrm{kN} / \mathrm{m}^{2}\right)$ and sheared at $50 \mathrm{kN} / \mathrm{m}^{2}$ confining stress

\section{REFERENCES}

Clough, G. W., Sitar, N., Bachus, R. C. \& Rad, N. S. (1981). Cemented sands under static loading. J. Geotech. Engng, ASCE 107, 799-817.

Huang, J. T. \& Airey, D. W. (1998) Properties of artificially cemented carbonate sand. J. Geotech. Geoenviron. Engng, ASCE 124, 492-499.

Lambe, T. W. \& Whitman, R. V. (1969). Soil mechanics. New York: Wiley.

Mehta, P. K. \& Monteiro, P. J. M. (1993). Concrete: structure, properties and materials, 2nd edn. Englewood Cliffs, NJ: Prentice Hall.

Schofield, A. \& Wroth, P. (1968). Critical state soil mechanics. New York: McGraw-Hill.

Terzaghi, K., Peck, R. B. \& Mesri, G. (1996). Soil mechanics in engineering practice, 3rd edn. New York: Wiley.

Wood, D. M. (1990). Soil behaviour and critical state soil mechanics. Cambridge: Cambridge University Press. 